\title{
Polyploidy From Twin Seedlings
}

\author{
$\mathrm{By}$ \\ Arne Müntzing \\ Svalöf, Sweden
}

\section{Introduction}

Recently two Japanese scientists, Namikawa and KaWAKami (1934), have briefly reported some rather interesting results concerning the chromosome numbers of twin seedlings in wheat. In crosses between varieties of Triticum vulgare the occurrence of twin seedlings was observed. The chromosome numbers of these twin plants were determined and in some cases were found to differ from the normal number. Of a total of 29 twin pairs studied, 19 were found to be normal in chromosome number, both twins in each pair having $2 \mathrm{n}=42$. In 10 cases, however, the twins had different chromosome numbers, one member of the pair generally having $2 \mathrm{n}=63$, the other one $2 n=42$. This was found in eight cases. In another two pairs the chromosome numbers of the twin plants were $42-21$ and $42-84$ respectively. Consequently, by selection of twin plants NAMIKAWA and KAWAKAMI, in a rather limited material, succeeded in obtaining wheat plants with 21,63 and 84 chromosomes, besides normal plants with $2 \mathrm{n}=42$.

Being occupied with problems of polyploidy, especially in cultivated plants, the present writer decided to repeat, if possible, the work of NAMIKAWA and KAWAKAMI. Further, as selection of polyploids from twin plants might be possible also in other cultivated plants than wheat, the work was also extended to include other cereals and different species of forage crop plants, etc.

The twin material studied was in part produced from germination experiments of our own, performed in the laboratory of the cyto-genetic department at Svalöf. Seeds of winter wheat and rye were germinated (between moist blotting paper) in the autumn of 1935, summer wheat, barley and oats in the spring of 1936 . Most of the material, however, was obtained from the seed control stations at Svalöf and Åkarp, Sweden. For this material I am very much indebted to Dr. H. Christoffersson, Dr. O. Tedin and Mr. A. GÄRSNER. From these gentlemen I learned that twin seedlings are not infrequently met with during seed control work. Collections of twin seedlings of wheat, oats and barley had even been brought together and preserved by Dr. ChristofFERsson. In view of this 
information the possibility of obtaining twin plants in various species of cultivated plants seemed to be rather promising, and during the winter of 1935-1936 rather large numbers of twin seedlings were in fact obtained from the seed control stations mentioned.

The twin plants received were separated from each other at an early stage, simply by cutting the two plants apart with the aid of a sharp knife. After separation, each plant was placed in a separate pot, and root tips were fixed in chrom-acetic formalin. As most of the plants were received during the winter time they were kept growing under electric light, the installation of electric light for winter cultures, available at Svalöf, being utilized for that purpose.

\section{The frequency of twin plants}

Up to now twin seedlings have been obtained from the following species: Triticum vulgare, (winter and summer wheat), Triticum turgidum, Secale cereale, (winter and summer rye), Avena sativa, Hordeum vulgare, Phleum pratense, Dactylis glomerata, Lolium perenne, Poa pratensis, Agrostis stolonifera, Festuca pratensis, Festuca ovina, Festuca rubra, Festuca duriuscula, Cynosurus cristatus, Medicago sativa, Trifolium pratense, Beta vulgaris, Daucus carota and Solanum tuberosum.

The ratio of normal: twin seedlings could not be calculated this year for the material coming from the seed control stations, but data are available from our own germinations. These, however, only include the cereals, wheat, rye, barley and oats. The frequency of twin seedlings in this material is given in Table 1.

In Linum, KAPPERT (1933) found that strains producing a high proportion of twin seedlings could be selected in the progeny of crosses between parent strains, giving a low frequency. Further, as the twin seedlings of wheat, studied by NAMIKAWA and KAwAKAMI (l.c.), were found in $F_{3^{-}}$and $F_{4}$-progenies of certain intervarietal crosses, a similar heterozygous material of winter wheat was kindly placed at my disposal by Prof. §. Åkerman, Svalöf. This material consisted of seeds from $F_{2^{-}}, F_{3}, F_{4^{-}}, F_{5^{-}}$and $F_{6^{-}}$progenies of different crosses between varieties of Triticum vulgare. For cor:parison seeds of the commercial variety "Skandia"-wheat, which may be considered to be completely or almost completely homozygous, were also germinated.

As is evident from Table 1 there is no significant difference between the percentage of twin seedlings in the homozygous and heterozygous material. In both categories the frequency is low, approximately one twin pair being obtained from one thousand seeds. The exact values are $0,89 \pm 0,27$ per mille for Skandia-wheat and 
$0,99 \pm 0,21$ per mille for the $F_{2}-F_{6}$ material. A comparison between the frequency of twin seedlings in the different generations

Table 1. The frequency of twin seedlings in some cereals

\begin{tabular}{|c|c|c|c|c|}
\hline Species & $\begin{array}{c}\text { Fueld number } \\
\text { or commercial } \\
\text { variety }\end{array}$ & $\begin{array}{l}\text { Number of } \\
\text { seeds }\end{array}$ & $\begin{array}{l}\text { Number of } \\
\text { twin pairs }\end{array}$ & $\begin{array}{l}\text { Twin pairs } \\
\text { per mille }\end{array}$ \\
\hline $\begin{array}{c}\text { Triticum vulgare } \\
\text { winter wheat } \\
\text { ", } \\
\text { ", } \\
\text { ", } \\
\text { ", } \\
\text { ", } \\
\text { ", } \\
\text { ", } \\
\text { ", }\end{array}$ & $\begin{array}{l}\text { Skandia } \\
1057\left(\mathrm{~F}_{2}\right) \\
1058\left(\mathrm{~F}_{2}\right) \\
1059\left(\mathrm{~F}_{2}\right) \\
1062\left(\mathrm{~F}_{2}\right) \\
1063\left(\mathrm{~F}_{2}\right) \\
1064\left(\mathrm{~F}_{2}\right) \\
1061\left(\mathrm{~F}_{3}\right) \\
1081\left(\mathrm{~F}_{3}\right) \\
1083\left(\mathrm{~F}_{3}\right) \\
1085\left(\mathrm{~F}_{3}\right) \\
1073\left(\mathrm{~F}_{4}\right) \\
1080\left(\mathrm{~F}_{4}\right) \\
1069\left(\mathrm{~F}_{5}\right) \\
1086\left(\mathrm{~F}_{6}\right)\end{array}$ & $\begin{array}{r}12,305 \\
3,064 \\
1,244 \\
1,225 \\
1,558 \\
1,550 \\
711 \\
1,588 \\
2,246 \\
3,072 \\
1,525 \\
1,200 \\
1,457 \\
1,369 \\
1,336 \\
\end{array}$ & $\begin{array}{r}11 \\
5 \\
4 \\
1 \\
0 \\
2 \\
1 \\
0 \\
0 \\
2 \\
1 \\
2 \\
3 \\
1 \\
1\end{array}$ & \\
\hline $\begin{array}{c}\text { Triticum vulgare } \\
\text { summer wheat } \\
, \\
, \\
\text { " }\end{array}$ & \begin{tabular}{|c|} 
Fylgia \\
Diamant \\
Extra KolbenIII \\
"Varvete"
\end{tabular} & $\begin{array}{l}2,490 \\
2,700 \\
2,050 \\
1,720 \\
\end{array}$ & $\begin{array}{l}1 \\
3 \\
1 \\
1\end{array}$ & \\
\hline $\begin{array}{l}\text { Triticum vulgare } \\
\text { total }\end{array}$ & & 44,410 & 40 & $0,90 \pm 0,14$ \\
\hline Triticumturgidum & 2,210 & 18,856 & 3 & $0,16 \pm 0,09$ \\
\hline $\begin{array}{c}\text { Secale cereale } \\
\text { ", }\end{array}$ & $\begin{array}{c}\text { Kungsråg } \\
\text { Stålåg } \\
0305\end{array}$ & $\begin{array}{r}10,308 \\
6,667 \\
389\end{array}$ & $\begin{array}{r}6 \\
19 \\
0 \\
\end{array}$ & \\
\hline $\begin{array}{l}\text { Secale cereale } \\
\text { total }\end{array}$ & & 17,364 & 25 & $1,44 \pm 0,29$ \\
\hline $\begin{array}{c}\text { Avena sativa } \\
\text { ", } \\
\text { ", } \\
\text { ", }\end{array}$ & $\begin{array}{c}\text { Orion } \\
\text { Seger } \\
\text { Orn } \\
\text { Gullregn 1I } \\
\text { Stormogul II } \\
\text { "Havre" }\end{array}$ & $\begin{array}{r}2,050 \\
3,250 \\
500 \\
3,150 \\
3,610 \\
821\end{array}$ & $\begin{array}{l}0 \\
0 \\
0 \\
0 \\
1 \\
0\end{array}$ & \\
\hline $\begin{array}{c}\text { Avena sativa } \\
\text { to.al }\end{array}$ & & 13,381 & 1 & $0,07 \pm 0,07$ \\
\hline $\begin{array}{c}\text { Hordeum vulgare } \\
\text { ", } \\
\text { ", } \\
\text { "' } \\
\text { ", }\end{array}$ & \begin{tabular}{|c|} 
Gullkorn \\
2 III \\
Kenia \\
Brio \\
Maja \\
Seger $\times$ Binder \\
Vega \\
Opal \\
\end{tabular} & $\begin{array}{r}1,900 \\
17,113 \\
4,033 \\
5,653 \\
1,975 \\
2,100 \\
4,450 \\
4,281 \\
\end{array}$ & $\begin{array}{l}0 \\
0 \\
1 \\
1 \\
1 \\
2 \\
1 \\
1\end{array}$ & \\
\hline $\begin{array}{c}\text { Hordeum vulgare } \\
\text { total }\end{array}$ & & 41,505 & 7 & $0,17 \pm 0,06$ \\
\hline
\end{tabular}


$\left(F_{2}-F_{6}\right)$ of the latter material did not reveal any significant differences either.

In summer wheat a similar frequency of twin seedlings as in winter wheat was obtained, 8960 seeds from four different commercial varieties giving 6 twin pairs. If all data for Triticum vulgare are added, the resulting figures will be 44410 seeds and 40 twin pairs. This gives a frequency value of $0,90 \pm 0,14$ per mille.

In Triticum turgidum only 3 seeds out of 18856 gave twin plants, which corresponds to the value $0,16 \pm 0,09$ per mille. This value is much lower than that found for Triticum vulgare $(0,90 \pm 0,14)$, and, evidently, the difference is statistically significant.

In rye three different commercial varieties were tested. A similar or slightly higher percentage was found, 25 twin pairs being obtained from 17364 seeds. This corresponds to $1,44 \pm 0,29$ per mille. The variety "Stâlråg" gives a higher proportion of twins than "Kungsråg", the difference being significant $(D / m=3,78)$.

Also in barley and oats a low proportion of twin seedlings was obtained from germination experiments with a number of commercial varieties ( $\mathrm{cf}$. Table 1 ). The average values were found to be $0,17 \pm$ 0,06 per mille in barley and $0,07 \pm 0,07$ in oats.

Oats and barley thus seem to give a lower proportion of twin seedlings than Triticum vulgare and rye, the data hitherto accumulated demonstrating significant differences. The main point, however, is the fact that all the cereals tested have given quite a low proportion of twin seedlings, generally less than one twin pair per mille being obtained.

\section{Chromosome counts}

The entire twin material obtained from the seed control stations and from our own germinations has not yet been completely investigated as to the chromosome numbers. However, the data hitherto accumulated (cf. Table 2) are sufficient to show that selection of twin seedlings is an important method of obtaining heteroploid plants not only in wheat but also in several other species. The results may be given under the following two headings: A) species in which all the twins had the same chromosome number and B) species in which some twins had deviating chromosome numbers.

\section{A. Species in which all twin plants had the same chromosome number}

a) Dactylis

In Dactylis glomerata the chromosome number was found to be 28 or \pm 28 in each member of 40 twin pairs. In seven cases one of the twins in each pair had died before fixation but the remaining 
single plants all had \pm 28 chromosomes, which is the normal number of the species.

b) Hordeum

In barley all the members of seven complete pairs had $2 \mathrm{n}=14$, just as four single plants, of which the corresponding twins had died at an early stage. One single plant of the same category had tetraploid sectors in some roots but died before a re-investigation could be made. Tetraploid sectors in root tips are frequent after heat treatment (unpublished results) and may even occur spontaneously in exceptional cases. Probably the sectors found in the plant mentioned had nothing to do with its origin as a twin seedling.

c) Festuca

Four complete pairs and one single plant of Festuca pratensis had all the normal chromosome number $2 \mathrm{n}=14$. One pair and two single plants of Festuca ovina had $2 \mathrm{n}=42$ and one pair of Festuca rubra $2 \mathrm{n}= \pm 56$. A single twin plant from another biotype of the same species had $2 \mathrm{n}=42$.

d) Scattered observations from other genera

In the following species all twin plants studied had also unchanged chromosome numbers: Agrostis stolonifera, $2 \mathrm{n}= \pm 42, \quad(4$ pairs, 1 single twin plant) ; Cynosurus cristatus, $2 \mathrm{n}=14$, (1 pair, 1 single plant); Beta vulgaris, $2 \mathrm{n}=18$, (1 triplet, 1 pair and 2 single twin plants).

\section{B. Species in which heteroploid twin plants were found}

\section{a) Triticum}

As the results of NAMIKAWA and KAWAKAMI (1934) in wheat was the direct cause of the present investigation, it seemed desirable in the first place to procure twin material of Triticum vulgare. Such twins were in fact obtained in the autumn of 1935, in part from germination experiments of our own, in part from the seed control stations. Unfortunately, however, these winter wheat twins were obtained rather late in the season, and therefore mortality among this material was very high. About half of the twin plants of $T$. vulgare did not survive the winter, though they were growing in boxes, placed in a hot-bed. Only part of the material could be fixed in the autumn. The chromosome numbers of the remaining individuals were determined in the spring and summer of 1936. Data are available for 19 complete pairs and 20 single plants. Of these 58 plants not less than 57 had the normal chromosome number 42 , but one twin plant was found to have $2 n= \pm 63$. This plant, however, died during the winter. Nevertheless, the occurrence of this 
single plant is sufficient to confirm the main result of NAMIKAWA and KAWAKAMI, viz. that individuals with deviating chromosome numbers may be found among twin seedlings of wheat.

The frequency in our case seems to be lower. This, however, may be apparent only, since mortality in our material was high and the twins from the same seed generally differ markedly in vigour. As will be further shown below the seedlings with deviating chromosome numbers are generally found among the weaker members of the twin pairs (cf. fig. 5 in the paper by NAMIKaWA and KAWAKAMI). Consequently mortality will be selective and tend to decrease the number of plants with deviating chromosome numbers.

Twin seedlings of Triticum vulgare were also obtained in summer wheat, but chromosome counts could only be made as regards two complete pairs and five single plants. All these nine plants had the normal number 42 . Of the twin partners of the five single plants mentioned, one had died before fixation. With regard to the other four the root tip fixations were unsuccessful, no countable chromosome plates being present. However, at least one of these four plants, of which the chromosome numbers are not known, mut have a deviating chromosome number. Judging from its reduced fertility and slightly deviating morphology this plant is most probably another 63-chromosome individual. This will be settled by chromosome counts of the progeny.

In Triticum turgidum three twin pairs were produced from a total of 18856 seeds. Fortunately all six twin plants survived the winter and could be examined cytologically. The result of this examination was interesting. In one of the pairs both plants had 28 chromosomes but in each of the other two pairs one twin had $2 \mathrm{n}=$ 28 , the other one $2 \mathrm{n}=42$ (Fig. 1 ). This result definitely shows that also in other Triticum species than vulgare, twin seedlings with deviating chromosome numbers may be formed.

\section{b) Secale}

In rye 17 twin pairs and 10 single twin plants were available for cytological examination. In addition there was also a group of three plants, originating from the same seed, which consequently were triplets. In the entire material, consisting of 47 plants, there was one individual with a deviating chromosome number. This plant proved to be triploid $(2 \mathrm{n}=21$, Fig. 3 ) while all the other plants had, as usual, 14 chromosomes.

c) Avena

In Avena sativa not less than four twin plants with deviating chromosome numbers were found among 16 twin pairs and 2 single 
twin plants. These four plants all had $2 n= \pm 63$ (Fig. 2) while the corresponding twins and the rest of the material were hexaploid as usual $(2 n=42)$.

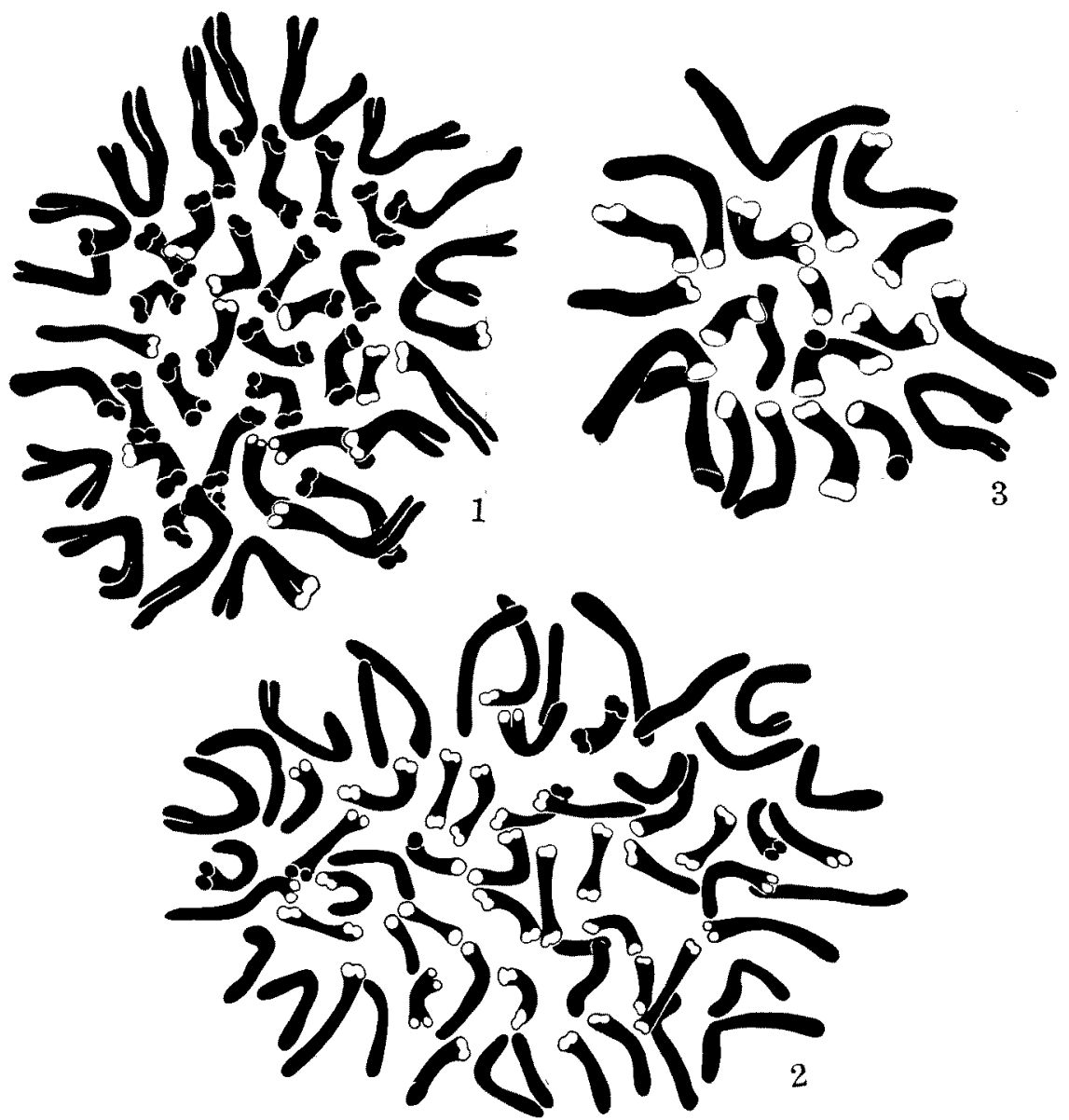

Figs. 1-3. Somatic plates of twin seedlings with deviating chromosome numbers. 1. Triticum turgidum $(2 \mathrm{n}=42)$. 2. Avena sativa $(2 \mathrm{n}=63)$. 3. Secale cereale $(2 \mathrm{n}=21)$.

\section{d) Phleum}

In Phleum pratense a relatively large number of twins were investigated, the material available consisting of 45 pairs and 20 single twins. Four plants with deviating chromosome numbers were obtained, three plants having $2 n= \pm 63$ and the fourth $2 n=21$. All the other individuals had \pm 42 chromosomes, which is the normal chromosome number of timothy. The appearance of a haploid timothy plant is especially noteworthy. This plant and a similar individual in Solanum tuberosum (cf. below) are the only haploids hitherto obtained in our entire twin material. 
Table 2. The frequency of twin plants with deviating chromosome numbers

\begin{tabular}{l|c|c|c}
\hline Species & $\begin{array}{c}\text { Number of twin } \\
\text { plants examined }\end{array}$ & $\begin{array}{c}\text { Number of twins } \\
\text { with deviating chro- } \\
\text { mosome numbers }\end{array}$ & $\begin{array}{c}\text { Percentage of } \\
\text { deviating twins }\end{array}$ \\
\hline Triticum vulgare & 67 & 1 & 1 \\
turgidum & 6 & 2 & 33 \\
Secale cereale & 47 & 1 & 2 \\
Avena sativa & 34 & 4 & 12 \\
Hordeum vulgare & 19 & - & 0 \\
Phleum pratense & 110 & - & 0 \\
Dactylis glomerata & 87 & - & 0 \\
Festuca pratensis & 9 & - & 0 \\
ovina & 4 & 2 & 5 \\
Lolium perenne & 3 & - & 0 \\
Agrostis stolonifera & 38 & 10 & 18 \\
Cynosurus cristatus & 9 & 1 & 25 \\
Poa pratensis & 3 & 25 & 5 \\
Solanum tuberosum & 46 & & \\
\hline Total & 4 & &
\end{tabular}

\section{e) Poa}

The observations in the genus Poa are so far limited to $P o a$ pratensis. In this species the frequency of twins with deviating chromosome numbers seems to be unusually high. A total of 19 pairs, one triplet and 15 single twin plants comprised not less than 10 plants with deviating chromosome numbers. As demonstrated in a previous publication (MÜNTZING 1932) Poa pratensis is apomictic and very polymorphic. Different biotypes of the species have generally different, and aneuploid, chromosome numbers, which in the main range from about 50-100 (MüNTZING 1932 and unpublished results, RANCKEN 1934, ÅKERBERG 1936).

The twin material now studied also belonged to different biotypes, differing in chromosome number. As the numbers are relatively high they have not yet been exactly determined and may need future correction to some extent. This is also the case with respect to those twin plants which have clearly deviating chromosome numbers. In the main, however, the following situation was met with:

In one variety ("3003") 12 of the examined plants had $2 n= \pm 48$. Four plants, however, had clearly different numbers, viz. $2 \mathrm{n}= \pm 78$, \pm 72 , \pm 71 and \pm 62 respectively. In the next variety ("3009") 18 individuals had approximately 68 chromosomes, but one individual had $2 \mathrm{n}= \pm 100$. In the variety " 3019 " only 5 plants have hitherto been examined and these had all $2 \mathrm{n}= \pm 69$. In a fourth variety, however, clearly deviating individuals were again met with. Four plants had approximately $76,80,65$ and 72 , chromosomes respectively, while the remaining four plants had $2 n= \pm 52$. In a fifth 
variety ("3645") again, five plants had \pm 51 chromosomes, but one plant had $2 \mathrm{n}= \pm 72$ :

Owing to the intraspecific chromosome variation the state of things in Poa pratensis is less clear than in the other genera studied, but nevertheless it is evident that in the main the twins of Poa pratensis behave in the same way. Usually the members of a twin pair have the same chromosome number, but relatively often one of the twins is approximately triploid in comparison with the other one. Of the ten plants, which were found to have deviating chromosome numbers, two were now single plants, the corresponding twins of which had died at an early stage. The remaining eight plants, however, belonged to six twin pairs and to one triplet, in which the chromosome numbers of all the members had been examined. In the triplet, two of the plants had the normal number \pm 48 , the third plant had \pm 71 . In five of the six twin pairs one member of the pair had the normal number of the strain, the other member being approximately triploid (in comparison with the normal number). Thus the following numbers were found: $\pm 48- \pm 78, \pm 49- \pm 72$, $\pm 52- \pm 76, \pm 52- \pm 72$ and $\pm 68- \pm 100$. Finally, in the sixth pair the plants were found to have \pm 65 and \pm 80 chromosomes. Both these values are higher than the normal number of the strain $( \pm 52)$.

\section{f) Lolium}

In perennial rye-grass, Lolium perenne, two plants with deviating chromosome number were found among 15 pairs, one triplet and 5 single plants. The two deviating plants were both triploid $(2 \mathrm{n}=$ $21)$ while the normal number of Lolium perenne $(2 \mathrm{n}=14)$ was found in the rest of the material. It should be emphasized that, contrary to the rule, in this case both these deviating twin plants belonged to the same twin pair.

\section{g) Solanum}

Two twin pairs have also been observed in the potato cultures of Dr. R. LAMM, working at the cyto-genetic department of Svalöf. One of the twin pairs was obtained in a tetraploid south-American variety (Solanum andigenum), the other pair from a tetraploid segregation product of the cross triploid south American $\times$ tetraploid European variety. Dr. LAMM has kindly informed me that both members of the first pair have 48 chromosomes whereas in the second pair one of the twins has 48 the other one 24 chromosomes. The latter individual consequently represents a haploid potato plant. 


\section{Morphology and fertility of the twin plants with deviating chromosome numbers}

Under this heading only a few preliminary remarks will be made concerning vigour and fertility of the plants with deviating chromosome numbers. Some of these plants are now in flower, others have not yet started to bloom. Detailed accounts will follow in future papers in connection with studies of the progeny from such plants.

In wheat the turgidum twins with 42 chromosomes have normal vigour and are at present (August 1936) rather similar to the normal turgidum-plants. The quality of the pollen is poor, however, and seed setting very low, though the anthers dehisce. The same thing is true of one vulgare-plant, which has probably $2 \mathrm{n}=63$.

The triploid rye individual $(2 n=21)$ is quite similar to a normal rye plant but is possibly slightly more vigorous. Pollen fertility is surprisingly good, the percentage of apparently good pollen being almost as high as in normal rye. Though the anthers dehisce no seed was obtained from isolation of the first ear that flowered.

In oats most of the twin material obtained was received early in spring and had to be cultivated under artificial light in a greenhouse. On account of this treatment the plants were all infected by various diseases and in spite of transplantation into the open air they have not reached normal vigour. Therefore, morphological studies are at present out of the question. Fertility, however, is rather good in the 63-chromosome plants, and a fairly large number of seeds has already been obtained from self-fertilization.

The 63-chromosome plants of Phleum pratense seem to be slightly more vigorous than their corresponding twins, having the normal number 42. Different twin pairs, however, behave somewhat differently in this respect. Pollen fertility is surprisingly good in the 63-chromosome individuals, almost as good as in normal timothy. From a theoretical point of view the haploid timothy plant $(2 n=21)$ is quite interesting, especially with respect to the probable origin of Phleum pratense from crosses between diploid and tetraploid Phleum species (GREGor and SANSOME 1930). Morphologically the haploid, as expected, is rather slender and has thinner and narrower leaves than the sister twin with $2 \mathrm{n}=42$. Also the culms are smaller and narrower in the haploid. Attempts to study meiosis in the haploid have hitherto been unsuccessful, since the anthers or at least the p.m.c. degenerated before meiosis. During the period of flowering, however, the plant was kept in a rather hot greenhouse, and a better result may perhaps be obtained under more favourable en- 
vironmental conditions. The haploid potato plant is quite weak and has much narrower and thinner leaves than the corresponding tetraploid twin.

The two triploid twins of Lolium perenne are definitely more vigorous and have broader and thicker leaves than diploid plants from the same material. The same thing is true of the twins in Poa pratensis. At first sight the twins with an increased number of chromosomes may be distinguished from their low-numbered sister plants. The twins in Lolium, Poa and Solanum have not yet reached the flowering stage.

\section{The origin of the twins with deviating chromosome numbers}

From the report given above it is evident that twin plants have a tendency to get deviating chromosome numbers. Obviously this must in some way be connected with those cytological and embryological processes which lead to the formation of twin plants. These processes may only be elucidated in detail by direct embryological investigations, but owing to the very low frequency of twin seedlings it is practically hopeless to carry out such studies in the present material. In the cross-fertilizing species, such as rye and timothy, it may be possible, however, by continued selection of twin plants to increase the rate of twin formation and thus facilitate an embryological examination.-Pending such investigations a working hypothesis may nevertheless be suggested on the basis of the following facts :

a) The twin plants studied have generally the same chromosome number, but when the numbers are different one of the twins is generally triploid as compared to the other one.

b) Rather frequently the two twins are very different in vigour at an early stage, one of the twins being of normal size, the other having markedly reduced dimensions. This is evident from fig. 5 in the paper by NAMIKAWA and KAWAKAMI (1934), but is often much more pronounced. This difference in vigour strongly indicates that one of the twins has been formed in an embryologically abnormal way. This means a poor start for such a twin seedling, but at least if the twins are separated the weak dwarf seedling may ultimately develop into a quite vigorous plant. Now the plants with deviating chromosome numbers in the majority of cases come from such weak seedlings.

The twin material studied was labelled as a- and b-plants, the latter representing the weaker members of the twin seedlings. The difference between the a- and b-plants is not always distinct, and 
sometimes both twins have just the same vigour. On an average, however, there is a manifest difference between the two categories, In the entire twin material hitherto examined 25 plants were found to have chromosome numbers deviating from the normal somatic number. Only five of these plants were a-plants, 19 individuals belonged to the b-category and one plant, from a triplet in Poa pratensis, was a c-plant (i.e. the weakest member of the triplet). Adding this plant to the b-group, it is evident that there is a significantly higher proportion of deviating b-plants than a-plants. The observed relation between $a$ and $b$ is $0,4: 1,6 \pm 0,20$. These values, evidently, cannot represent a $1: 1$ distribution $\left(D / m_{D}=3,0\right)$.

Judging from the premises given above under a) and $b$ ) the most probable origin of the twin plants with deviating chromosome numbers seems to be the following. Though in the family Gramineae there is generally only one macrospore mother cell in the nucellus there may occur two (or even three) such cells in exceptional cases. From each of these cells an embryo sac will develop. (In barley the present writer has observed the exceptional presence of two embryo sacs instead of one). As a rule both of these embryo sacs will have the reduced chromosome number and both will be fertilized. Sometimes, however, only the "normal" embryo sac will be reduced, the other one developing without reduction from the other macrospore mother cell. It seems plausible to assume that this accessory macros. pore mother cell may have a vegetative tendency, which sometimes leads to non-reduction. If this unreduced embryo sac is fertilized at the same time as the reduced one, the typical result will be obtained: one diploid and one triploid twin seedling.

For two reasons the triploid seedling will be weaker than the diploid one. Firstly, the normal, reduced embryo sac has probably a more favourable position in the nucellus and will be better nourished than the other one, and secondly, the relations between the chromosome numbers of embryo, endosperm and surrounding tissues in the unreduced embryo sac will be equal to $3 \mathrm{n}, 5 \mathrm{n}$ and $2 \mathrm{n}$ respectively, instead of $2 n, 3 n$ and $2 n$ characteristic of the normal embryo sac. Much evidence is available which demonstrates that such deviations from the normal $2: 3: 2$ ratio have a very pronounced effect on the viability of the embryos and hence probably also on the viability of the young seedlings (cf. MÜNTZING 1930, 1933, 1936).

The origin of haploids and tetraploids from twin seedlings remains to be considered. Though much rarer than the triploids, haploids have arisen not only in the twin material of NAMIKAWA and KAWAKAMI (1934) and in my own experiments but were also observed by KAPPERT (1933), working with Linum. According to 
NAMIKAWA and KAWAKAMI (l.c.) a haploid plant of Oryza sativa has also been obtained from twin material (RAMIH, PARTHASARTHI and RAMANUJAM, 1933).- It may be assumed that the haploids arise from one member of twin embryo sacs, which are both reduced. Only one of them will be fertilized, which stimulates the other to parthenogenetic development. The origin of tetraploid twin seedlings (NAMIKAWA and KaWAKAMI l.c., 1 plant) is more difficult to imagine. Most probably this implies somatic doubling after fertilization, or possibly doubling at the beginning of the embryo development, if this has started parthenogenetically,

The exceptional production of one twin pair in Lolium perenne, in which both members were triploid, and a similar case in Poa pratensis, shows that the explanations given above do not cover all cases. In the case of Lolium it is more probable that both twins are derived from the same macrospore mother cell. Meiosis in this cell, however, has probably stopped at the formation of two unreduced daughter cells, from which two unreduced embryo sacs have developed. Both of these have been fertilized and this has resulted in the formation of two triploid twin embryos.

From his genetical and embryological results in Linum, KAPPERT (1933) is forced to conclude that in this genus the observed haploids are derived from the same embryo sac as the diploid twins, i.e. by parthenogenetic development of another cell than the egg cell. KAPPERT has also demonstrated that, as a rule, the diploid twins in Linum are genotypically indentical, having arisen by the splitting of one original embryo. As triploids were much more frequent than haploids in our twin material it seems necessary to assume that at least in the case of the triploids the twins develop from two different embryo sacs. The most frequent twin category, however, in which both members are diploid, may perhaps also in our material result from the splitting of one original embryo. This may be decided by future genetical and morphological studies, and is already strongly indicated by preliminary observations in Phleum, Dactylis and Festuca. On the other hand it seems rather probable that triploids may also occur among the Linum twins. Triploids are generally less conspicuous than haploids and may have been overlooked in KAPPERT's Linum material.

\section{The theoretical and practical importance of the twin method}

As problems of polyploidy in plants are at present of a rather central interest, it would be highly desirable to obtain a good method of artificial production of polyploids. No such method, however, 
comparable e.g. to the X-ray method of inducing mutations, is at present available. Scattered positive results have been obtained by various methods. Of these the method of species hybridization, leading to allopolyploids, has on an average been the most effective one. The result of a species cross, however, depends much more on the nature of the material than on the intentions of the worker. With regard to autopolyploidy the regeneration method has given beautiful results in the mosses but is restricted to this plant group, just as the decapitation method can only be used in Solanum and a few other genera. The method of influencing the meiotic divisions by external agencies in order to obtain unreduced gametes and polyploid progeny is also rather difficult and does seldom lead to a regular production of polyploids.

The method introduced by RANDOLPH (1932) is the first really promising method, since in some cases it has lead to the production of a low but regular frequency of plants with doubled chromosome number. This result was obtained in maize by the application of high temperature at the time when the fertilized ovules begin to divide. Recently DoRSEY (1936), using the same method, has also obtained positive results in rye and wheat. It may be added that after treatment with low temperature at the time of the first zygotic division, the present writer obtained a seedling of Triticum turgidum with doubled chromosome number $(2 n=56)$. This seedling, however, did not survive the winter. Though promising this heat (or frost) treatment method is not always an easy way to get polyploids. At Svalöf strenuous efforts have been made to obtain tetraploid barley by this method but hitherto the result has been mainly negative.

Consequently, in contrast to all the other ways, the twin method is evidently a relatively comfortable means of obtaining heteroploid forms. And further, as plant twins are known to occur in a large number of genera, the application of this method may be expected to be of a rather general importance. According to KAPPERT (1933), SCHNARF has reported the occurrence of polyembryony in not less than 136 genera.

A characteristic feature of the twin method is the production of triploids or, in some cases, more correctly of forms having a 50 per cent higher chromosome number than usual. This is at the same time advantageous and disadvantageous. On account of their odd chromosome number such individuals are not immediately constant but will give rise to series of new types with different chromosome numbers. In later generations, however, stable products with changed chromosome numbers should be obtained. As regards the 
final result different kinds of material will probably behave differently.

It is often difficult or impossible to obtain hybrids between polyploids and their original forms (cf. MüNTZING $1936 \mathrm{pp}$. 300-304 and 326-334). The polyploid twins, however, represent such hybrids with odd chromosome numbers and may therefore in some cases be more valuable for the production of heteroploid forms than stable and incompatible strains. Therefore, the twin method will probably be extensively used for future studies concerning viability, fertility, morphology and physiology of heteroploid plants. It should also be pointed out that the twin method may be valuable not only for the production of autopolyploids but indirectly also for the formation of allopolyploids. If stable autopolyploids of different constitution are crossed, constant and fertile allopolyploids may immediately be formed, owing to autosyndesis (cf. MÜNTZING 1936, p. 338).

The twin method opens new possibilities also in two other respects, viz. for the study of haploids and for studies on the nature of apomixis. Though the general cytological and genetical features of haploids have already been elucidated, it may for several reasons be of interest to produce haploids of as many species as possible. Especially interesting is the type of chromosome pairing in such haploids as contain more than one genome. If, for instance, meiosis can be studied in the haploid timothy plant referred to above, it should proceed along the same lines as meiosis in the triploid hybrid between Phleum alpinum and nodosum, since, presumably, these species $($ nodosum $=$ diploid pratense) are the ancestors of the hexaploid species $P$. pratense (GREgor and SANsome 1930).

As already pointed out by KAPPERT (1933) the facultative formation of twin embryos (or even larger numbers of embryos in the same seed) is of immediate interest in relation to the occurrence of habitual polyembryony in apomictic species.-In Poa pratensis, belonging to the present material, the occurrence of twin seedlings may directly be studied in relation to the nature of apomixis in this species. Pending more thorough studies, only a few features should be pointed out already now. The frequency of polyembryonic seeds is rather high in Poa pratensis and this is probably in some way correlated with the apomictic propagation, which is characteristic of the species. The occasional formation of "triploid" twin plants, however, resulting from fertilization of unreduced ovules, demonstrates that apomixis in Poa pratensis is not absolute. This is in accordance with the results of AKERBERG (1936), who succeeded in obtaining a few hybrids in Poa pratensis in addition to a majority of maternal offspring. These hybrids, however, just as the "triploid" 
twin seedlings, seem to result from the union of unreduced female and reduced male gametes (ÅkERBERG 1936, p. 238). Unreduced ovules have also been observed to function rather frequently in sexual strains of Poa alpina but, on the other hand, I have obtained "haploids" in Poa alpina in the offspring from hybrids between sexual and apomictic plants (unpublished results). Finally it should be mentioned that a "haploid" of Poa pratensis with $2 n=36$ has been obtained from an apomictic biotype with $2 \mathrm{n}=72$. The "hap. loid" type proved to be sexual and markedly sterile (MÜNTZING, un. published results). The high frequency of twin seedlings in Poa pratensis and the observed occurrence of twins with deviating chromosome number in this species makes it likely that this sexual haploid has arisen as a twin seedling.-

The production of twin plants with deviating chromosome num. bers is in itself very interesting. The main value of the phenomenon, however, is the fact that it represents a new method which may be used for the production of a rich material of heteroploid forms. In the first place this material gives rise to many new theoretical problems but may also be of practical importance. In several cases mentioned above the new products have gigas characters (Phleum, Lolium, $P o a$ ) and may possibly give rise to high-yielding varieties, either directly as in Poa (thanks to apomictic propagation) or indirectly after stabilization.

\section{Summary}

1) The chromosome numbers of twin seedlings in various species of cultivated plants have been examined. Though most of the twins have the normal chromosome number, twin seedlings with deviating chromosome numbers were found in the following species: Triticum vulgare, Triticum turgidum, Secale cereale, Avena sativa, Phleum pratense, Poa pratensis, Lolium perenne and Solanum tuberosum.

2) If the twin plants differ in chromosome number, one of the twins is generally triploid in relation to the other one. This may be due to simultaneous fertilization of reduced and unreduced embryo sacs.

3) Attention is called to the theoretical and practical impor. tance of the twin method. Though the twins are formed in a low frequency, a rich material may be obtained by cooperation with seed control stations. 


\section{Literature cited}

1) Dorsey, E. 1936. Induced polyploidy in wheat and rye.-Journ. of Heredity, Vol. 27, No. 4, pp. 155-160.

2) Gregor, J. W. and Sansome, F. W. 1930. Experiments on the genetics of wild populations. II. Phleum pratense L. and the hybrid P. pratense L. $\times$ P. alpinum L.-Journ. of Genetics, Vol. 22, No. 3, pp. 373-387.

3) Kappert, H. 1933. Erbliche Polyembryonie bei Linum usitatissimum.-Biolog. Zentralbl. Bd. 53, H. 5/6, ipp. 276-307.

4) Müntzing, A. 1930. Übar Chromosomenvermebrung in Galeopsis-Kreuzungen und ihre phylogenetische Bedeutung.-Hereditas 14, pp. 153-172.

5) - 1932. Apomictic and sexual seed formation in Poa.-Hereditas 17, pp. 131-154.

6) - 1933. Hybrid incompatibility and the origin of polyploidy.-Hereditas 18 , pp. 33-65.

7) - 1936. The evolutionary significance of autopolyploidy.-Hereditas 21, pp. 263-378.

8) Namikawa, S. and Kawakami, J. 1934. On the occurrence of the haploid, triploid and tetraploid plants in twin seedlings of common wheat.-Proc. of Imp. Acad. (Tokyo), Vol. 10, No. 10, pp. 668-671.

9) Ramih, K., Parthasarthi, N. and Ramanujam, S. 1933. Haploid plant in rice (Oryza sativa).-Current Sci. Mysore, Bd. 1, pp. 277-278.

10) Rancken, G. 1934. Zytologische Untersuchungen an einigen wirtschaftlich wertvollen Wiesengräsern.-Acta Agr. Fennica 29.

11) Randolph, L. F. 1932. Some effects of high temperature on polyploidy and other variations in maize.-Proc. of the National Academy of Sciences, Vol. 18, No. 3, pp. 222-223.

12) Åkerberg, E. 1936. Studien über die Samenbildung bei Poa pratensis L.-Botan. Notiser, pp. 213-280. 